THEORETICAL FOUNDATIONS OF THE FUNCTIONING OF EDUCATION. WAYS TO

IMPROVE THE EFFECTIVENESS OF EDUCATIONAL ACTIVITIES

\title{
2.2 Подходы к формированию готовности будущих педагогов к инновационной деятельности
}

В современных условиях роль институтов образования существенно возрастает. Становление и развитие инновационной экономики и общества, основанного на знаниях, невозможно без опережающего инновационного развития системы образования. В свою очередь, это определяет необходимость масштабного развертывания в системе образования инновационных процессов, которые, по мнению многих исследователей, становятся одной из его важнейших характеристик. По сути, инновационные преобразования практически всех составляющих образовательной системы выступают сегодня стержнем ее модернизации. Широкомасштабные реформы в образовательной сфере кардинальным образом меняют смысл и содержание педагогической деятельности, приводят к усложнению задач, стоящих перед педагогами, росту социальной значимости и ответственности их труда. Кроме того, в условиях реализации стратегии устойчивого социально-экономического развития и реформирования образования возрастает потребность в педагогических кадрах, которые не только готовы принимать, но и способны создавать инновации и активно включаться в процессы их внедрения. Успех перехода образования на путь инновационных преобразований определяется сбалансированным развитием двух базовых составляющих: развертыванием в системе образования инновационных процессов и формированием кадрового потенциала образовательных инноваций, причем второе направление выступает условием реализации первого, первое же, в свою очередь, становится средой, в которой аккумулируется инновационный потенциал, выступающий сегодня высшей формой человеческого капитала. А.В. Хуторской отмечает, что обусловленность инновационного характера современной педагогической деятельности определяется рядом обстоятельств [106]:

- необходимостью обновления системы образования, изменения методологии и технологии организации учебно-воспитательного процесса, где инновационная направленность деятельности педагогов, включающая в себя 
THEORETICAL FOUNDATIONS OF THE FUNCTIONING OF EDUCATION. WAYS TO IMPROVE THE EFFECTIVENESS OF EDUCATIONAL ACTIVITIES

создание, освоение и использование педагогических новшеств, выступает источником развития педагогической теории и образовательной практики;

- гуманитаризацией и индивидуализацией содержания образования, непрерывным изменением объема, состава учебных дисциплин, что требует постоянного поиска новых организационных форм и технологий обучения;

- изменением характера отношения педагогов к факту освоения и применения педагогических новшеств;

- становлением рынка образовательных услуг, возникновением конкуренции в сфере образования. Можно сформулировать основные идеи, лежащие в основе инновационного обновления системы образования:

- создание условий для инновационного развития образовательного учреждения и проявления творческих способностей педагогов и обучающихся;

- укрепление сотрудничества образовательного учреждения;

- ориентация на удовлетворение требований общества, государства, экономики к образованию;

- ориентация на удовлетворение образовательных потребностей личности, которые, в свою очередь, тесно связаны с требованиями различных социальных слоев, общностей людей, национальных, региональных и других особенностей;

- учет влияний, оказываемых на систему образования факторами внешней среды.

В современных условиях в системе образования ощущается острая нехватка кадров, обеспечивающих неразрывность инновационной цепочки, без чего невозможно обеспечить реальное и качественное, а не формальное обновление образовательной деятельности. Дефицит инновационных кадров требует перестройки системы непрерывного профессионально-педагогического образования и, в первую очередь, системы подготовки будущих педагогов в вузе. Одним из важнейших факторов развития инновационных процессов в образовании становится, таким образом, формирование готовности к инновационной деятельности будущих педагогов. Готовность к инновационной деятельности - это многоаспектный и многоплановый феномен, который 
THEORETICAL FOUNDATIONS OF THE FUNCTIONING OF EDUCATION. WAYS TO IMPROVE THE EFFECTIVENESS OF EDUCATIONAL ACTIVITIES

затрагивает как личностные, так и деятельностные характеристики. В.С. Лазарев определяет готовность к инновационной деятельности как совокупность качеств будущего педагога, определяющих его направленность на развитие собственной педагогической деятельности и деятельности всего коллектива, а также на его способность выявлять актуальные проблемы образования обучающихся, находить и реализовать эффективные способы их решения [99]. По мнению Н.Ю. Посталюк, феномен готовности к нововведениям - личностное проявление творческого стиля деятельности педагога, в котором своеобразным образом сочетаются антиконформизм интеллекта, личностная направленность как стремление, потребность реализовать новые педагогические идеи, практические умения осуществлять новые способы и формы профессиональной деятельности [102]. А.И. Пригожин полагает, главная характеристика субъекта инноваций его деятельное самосознание, т.е. понимание своей личной инициативы как субъективно возможной и общественно принимаемой основы собственного существования [103]. Необходимо отметить, что сегодня исследователи различают два типа инновационных феноменов в образовательной сфере: педагогическую инноватику (инновации в системе образования) и инновационное обучение. Если педагогическая инноватика связана с перестройкой, модификацией, усовершенствованием, изменением системы образования или ее отдельных элементов, свойств и аспектов, а инновационное обучение определяется как принципиально новый тип организации образовательного процесса, новые технологии овладения знаниями, изменившийся характер взаимодействия субъектов образовательного процесса. Поэтому, когда говорим о готовности педагогов к инновационной деятельности, должны иметь в виду, это понятие включает их способность работать в новых условиях, условиях инновационных изменений в системе образования, с другой стороны, характеризует их способность создавать и осваивать новые педагогические практики, т.е. осуществлять инновационное обучение. А также следует обратить внимание на что инновационная деятельность - это не особый вид или особая сфера труда, а его качественная характеристика, 
THEORETICAL FOUNDATIONS OF THE FUNCTIONING OF EDUCATION. WAYS TO

IMPROVE THE EFFECTIVENESS OF EDUCATIONAL ACTIVITIES

подчеркивающая специфичный характер деятельности. Инновационную деятельность невозможно очертить какой-либо предметной областью, поскольку любая деятельность и в любой сфере может быть инновационной, если в нее привносится новое (знания, технологии, приемы, подходы) для получения результата, отличающегося высокой востребованностью. Говоря о готовности к инновационной деятельности, надо ясно понимать ее общую структуру, а не только предметное содержание. Раскрывая содержание инновационной деятельности, А.В. Хуторской подчеркивает единство трех составляющих инновационного процесса: создание, освоение и применение новшеств [106]. В.С. Лазарев выделяет в структуре инновационного процесса четыре элемента [99]:

1. Создание новшеств:

- анализ образовательной деятельности и выявление потребности в изменениях;

- проектирование новшеств;

- экспериментальное апробирование новшеств;

- экспертиза новшеств.

2. Распространение новшеств:

- подготовка к распространению;

- информирование о новшествах;

- поддержка освоения новшеств;

- анализ распространения и освоения новшеств.

3. Освоение новшеств:

- анализ образовательной деятельности и выявление потребности в изменениях;

- поиск новшеств;

- оценка и выбор новшеств;

- проектирование желаемого будущего образовательной системы;

- внедрение новшеств;

- анализ и оценка результатов изменений; 
THEORETICAL FOUNDATIONS OF THE FUNCTIONING OF EDUCATION. WAYS TO

IMPROVE THE EFFECTIVENESS OF EDUCATIONAL ACTIVITIES

- институализация нововведений.

4. Обновленная образовательная деятельность. Соответственно этой структуре, формируя и оценивая готовность будущих педагогов к инновационной деятельности, должны осознавать, способность к осуществлению ее на каком из этих этапов. По мнению В.А. Сластенина, готовность к инновационной деятельности «должна включать в себя различного рода установки на осознание определенной задачи, модель вероятностного поведения, определения специальных способов деятельности, оценку своих возможностей в их отношении с предстоящими трудностями и необходимостью достижения определенного результата» [104]. С учетом этого формирование готовности будущих педагогов к инновационной деятельности предусматривает:

- способность анализировать мотивы и диспозиции педагогической деятельности;

- критическое отношение к педагогическим нормативам;

- рефлексию и построение системы смыслов;

- открытость среде и профессиональным новшествам;

- творчески преобразующее отношение к миру, выход за пределы нормативно заданного;

- стремление к самореализации, к воплощению в профессиональной деятельности своих намерений и образа жизни; субъективирование элементов содержания образовательной деятельности, наделение ее личностным смыслом [104]. В исследованиях В.А. Сластенина и Л.С. Подымовой раскрываются следующие компоненты готовности к инновационной деятельности: мотивационный, когнитивный, технологический, рефлексивный [104]. Мотивационный компонент при этом включает: интерес к новшеству, его принятие, готовность к освоению; стремление будущих учителей к изменению своей позиции в образовательном процессе; осознание цели и необходимости инновационной деятельности; стремление и потребность ее осуществлять. Мотивационная сфера традиционно выделяется как важнейший элемент продуктивной деятельности, который обусловливает целенаправленный, 
THEORETICAL FOUNDATIONS OF THE FUNCTIONING OF EDUCATION. WAYS TO IMPROVE THE EFFECTIVENESS OF EDUCATIONAL ACTIVITIES

сознательный характер действий человека и определяет его потенциал. Потребность в том или ином виде деятельности, в совершенствовании личности как субъекта этой деятельности выступает активным стимулом профессионального и личностного развития. Когнитивный аспект готовности к инновационной деятельности предполагает высокий уровень владения концептуальными и теоретическими основами исследовательской деятельности, ориентацией в современных подходах к решению педагогических проблем, наличие базирующейся на научных знаниях собственной педагогической философии, на основе которых происходит формирование соответствующих профессиональных умений. Технологический компонент формирования готовности к инновационной деятельности связан с организацией образовательного процесса, обеспечивающей приобретение в процессе обучения опыта инновационной деятельности, способности проектировать модели поведения, умений осуществлять выбор инновационной проблемы и темы исследования, уметь составлять программу экспериментальной и поисковой работы, владеть разнообразными способами введения новшеств в педагогический процесс, методикой диагностики и отслеживания результатов экспериментальной работы. Рефлексивный компонент готовности будущих педагогов к инновационной деятельности характеризует уровень осмысления, осознания мотивов, целей деятельности, развитие способностей к самоанализу своей деятельности и возникающих педагогических проблем, включает обращенность к своему внутреннему миру, опыту жизнедеятельности. Рефлексивный компонент готовности требует признания субъектности будущего педагога, учета приоритета субъект-субъектных отношений в процессе профессионально-педагогической подготовки. Многими исследователями отмечается необходимость формирования психологической готовности к инновационной деятельности, представляющей единство когнитивного, аффективного и конативного (деятельностного) компонентов [104]. Представляет интерес структура психологической готовности, выделенная С.П. Ивановой [96]. По мнению С.П.Ивановой, психологическая готовность к 
THEORETICAL FOUNDATIONS OF THE FUNCTIONING OF EDUCATION. WAYS TO IMPROVE THE EFFECTIVENESS OF EDUCATIONAL ACTIVITIES

деятельности может быть представлена четырьмя компонентами, в каждом из которых есть стартовая установка к тому или иному виду деятельности и одновременно способность к достижению необходимого результата: установка и способность к полному включению в деятельность; установка и способность к нестереотипной деятельности; установка и способность принятия обоснованного решения; установка и способность выдержать испытание стрессом. Е.П. Кораблина отмечает, что формирование готовности к инновационной деятельности включает в себя, кроме психологической готовности, становление профессиональной компетентности, готовность педагогов к решению профессиональных задач [105]. Ориентация на модель профессионального и личностного развития лежит в основе поведенческой модели подготовки будущих педагогов, которая реализуется по нескольким направлениям. Первое из них основано на метакогнитивной стратегии профессиональной деятельности, под которой понимается проектирование такого профессиональнообразовательного маршрута подготовки будущего педагога, результатом которого является получение знаний, опыта деятельности не только в рамках предметной области, но главным образом в рамках «общепредметного содержания» (В.В. Краевский, А.В. Хуторской). Второе направление определяется ценностными основаниями профессионально-педагогической деятельности. Третье направление связано с пониманием будущими педагогами содержания профессионально-педагогической деятельности, их готовностью к реализации собственной системы деятельности, конструированием собственного образовательного пространства, в котором воплощаются их профессиональные замыслы. Четвертое направление определяет способы осуществления педагогической деятельности в рамках локальной профессиональной среды, связано с «ансамблевым» видением организации образовательного процесса, в котором происходит обогащающее взаимодействие субъектов образовательной деятельности. В.А. Сластенин, подчеркивая важность социального взаимодействия для осуществления инновационной деятельности, отмечает, что педагог как субъект инновационной 
THEORETICAL FOUNDATIONS OF THE FUNCTIONING OF EDUCATION. WAYS TO IMPROVE THE EFFECTIVENESS OF EDUCATIONAL ACTIVITIES

деятельности и ее организатор вступает во взаимодействие с другими членами педагогического сообщества в процессах создания, использования и распространения новшества [104]. А.Н. Леонтьев указывает, что деятельность «...предполагает не только действия отдельно взятого человека, но и действия его в условиях деятельности других людей, т.е. предполагает некоторую совместную деятельность» [100]. Такое взаимодействие обеспечивает актуализацию инновационной культуры личности, так как вне его культура выступает лишь потенциальной возможностью инновационной деятельности. Очевидно, что процесс подготовки будущих педагогов к инновационной деятельности должен быть проектируемым и управляемым. Основными источниками информации при проектировании и создании системы подготовки будущих педагогов к инновационной деятельности могут выступать: социальный заказ общества; зарубежный и отечественный опыт подготовки специалистов к инновационной деятельности и изучение тенденций его развития; компетентностная модель современного педагога; теоретические концепции, раскрывающие проблемы подготовки будущих педагогов к инновационной деятельности; практический опыт подготовки педагогов к инновационной деятельности и пр. Управляемость и эффективность процесса подготовки будущих педагогов к инновационной деятельности обеспечивается специально созданными условиями, такими, в частности, как: преемственность всех этапов многоуровнего педагогического образования; ориентация обучения на обобщенную модель подготовки педагога к инновационной деятельности; организация мониторинга и диагностики готовности будущих педагогов к инновационной деятельности; формирование у будущих педагогов творческой активности и мотивационно-целостного отношения к педагогическим инновациям; взаимосвязь методологической, специальной, общепедагогической, методической подготовки будущего педагога; осуществление междисциплинарных взаимодействий, интеграция знаний проблем педагогической инноватики; формирование у будущих педагогов инновационной культуры, восприимчивости к новому; обеспечение 
THEORETICAL FOUNDATIONS OF THE FUNCTIONING OF EDUCATION. WAYS TO

IMPROVE THE EFFECTIVENESS OF EDUCATIONAL ACTIVITIES

системообразующих функций педагогической практики в ee единстве с исследовательской подготовкой; изучение и оценка динамики освоения инновационной деятельности будущими педагогами. Целенаправленное формирование готовности будущих педагогов к инновационной деятельности требует, создания условий, как:

- высокий уровень сформированной готовности к инновационной деятельности преподавателей, осуществляющих процесс подготовки будущих педагогов;

- включение будущих педагогов в реальную практику инновационного образования путем чередования индивидуальных (творческие задания), групповых (лекции, семинары) и коллективных (ролевые игры, дискуссии, тренинги) форм организации подготовки, направленной на формирование готовности к инновационной деятельности;

- овладение будущими педагогами приемами рефлексивного анализа собственной деятельности;

- применение в образовательном процессе информационных технологий для создания контекстных, проективных образовательных ситуаций.

Создание условий формирования готовности будущих педагогов к инновационной деятельности диагностируется через:

- уровень мотивации будущих педагогов к инновационной деятельности;

- степень их включенности в различные формы инновационной, проектной, исследовательской, опытно-экспериментальной деятельности;

- овладение ими приемами рефлексивного анализа инновационных процессов в системе образования и собственной деятельности;

- освоение и применение на практике современных моделей, технологий и инструментов инновационной деятельности.

Главная задача подготовки будущих педагогов к инновационной деятельности заключается, в том, чтобы способствовать самораскрытию обучающегося, «вытягивать» его потенциальные возможности, которые становятся основой активного профессионального и личностного саморазвития. 
THEORETICAL FOUNDATIONS OF THE FUNCTIONING OF EDUCATION. WAYS TO IMPROVE THE EFFECTIVENESS OF EDUCATIONAL ACTIVITIES

Объем знаний, которыми должен обладать современный педагог, весьма велик и разнообразен. Он включает в себя как проверенные временем научные истины и отработанные методы, непрерывно обновляющуюся и расширяющуюся информацию, появляющуюся в ответ на развитие педагогической науки и педагогической практики. Поэтому сегодня качество программ подготовки будущих педагогов к инновационной деятельности оценивается по способности построить образовательный процесс на основе синтеза науки и практики, обеспечить интеграцию исследовательского и учебного процесса, более того суметь вовлечь в исследовательскую работу. Современное образование знаменует собой переход от знаниевой к компетентностной модели, от информационно-сообщающего к интерактивному, деятельностному и практикоориентированному обучению. Компетентностный подход в подготовке специалиста к разнообразному спектру профессиональных задач обеспечивает учет социокультурного контекста и реализуется через набор продуктивных технологий подготовки:

- исследовательский характер профессиональной деятельности;

- проектные формы реализации профессиональных замыслов;

- ориентация на развитие субъектности будущего педагога в профессиональной деятельности. Достижение этой цели привносит в подготовку будущих педагогов компоненту, которая отсутствует в традиционном обучении, а именно: выработку и закрепление соответствующих навыков посредством тренингов, обучения действием, через решение реальных проблем, проектное обучение, организацию педагогических практик и т.п. Кроме того, центр тяжести перемещается с освоения книжного и даже «кейсового» материала на самообучение в группах, формирование навыков решения конкретных и актуальных проблем профессионально-педагогической деятельности посредством разработки и практической реализации прикладных проектов, проведения индивидуальных консультаций, обучения способам выдвижения и реализации инновационных идей, решения реальных профессиональных задач. Подготовка будущих педагогов к инновационной деятельности связана не 
THEORETICAL FOUNDATIONS OF THE FUNCTIONING OF EDUCATION. WAYS TO IMPROVE THE EFFECTIVENESS OF EDUCATIONAL ACTIVITIES

только и столько с передачей новых знаний, сколько с приобретением новых систем ценностей и качеств, необходимых для успеха инновационных процессов в образовании. Сегодня формирование личностных качеств, активной жизненной позиции, инновационного мышления становится приоритетом. Не менее важнее значение имеют социальная ответственность, осознание этических и нравственных норм и готовность им следовать, принятие и использование на практике гуманитарных технологий, понимание важности своей профессии, принадлежности к одному из наиболее значимых социальных институтов. Огромный потенциал имеют внедряемые в педагогический процесс современные образовательные технологии. При этом необходимо стремиться использовать разнообразные способы обучения, среди которых - групповые, игровые, рефлексивные методы, методы на основе полярностей, концептуальные методы, творчески конструктивные и иррациональные методы, решение реальных проблем, обучение на опыте, обучение на рабочем месте, обучение посредством анализа успехов и неудач, экспериментирование, выполнение исследовательских проектов и т.д. Большое значение имеет организация самостоятельной работы обучающимся. Учитывая особенности инноваций в образовании и требования, предъявляемые к современному педагогу, можно выделить два основных направления подготовки будущих педагогов к инновационной деятельности:

- связанное с планированием и организацией инновационного образовательного процесса;

- связанное с развитием личностных и профессиональных качеств будущего педагога, необходимых для инновационной деятельности. Первое направление предполагает формирование у будущих педагогов соответствующих профессиональных компетенций, обеспечивающих готовность проектировать новое учебное содержание, технологии и конкретные методики обучения. К необходимым умениям будущего педагога следует отнести умения осваивать ресурсы образовательных систем и проектировать их развитие, внедрять инновационные приемы в педагогический процесс с целью 
создания условий для эффективной мотивации обучающихся, выстраивать и реализовывать перспективные линии профессионального саморазвития с учетом инновационных процессов в образовании. Второе направление включает следующие аспекты:

- организация работы с информацией;

- самостоятельная разработка проектов и поиск источников их финансирования, развитие исследовательских навыков и умений;

- развитие умений самопрезентации;

- профессиональная самореализация;

- креативность;

- рефлексия и самооценка инновационной деятельности;

- диссеминация инновационного опыта.

Мы абсолютно убеждены, что переход от традиционной системы подготовки педагогических кадров к инновационному образованию - это, прежде всего, смена парадигм, отказ от стереотипов, устаревших схем мышления и действия, переход к формированию качественно нового образовательного пространства, которое создает условия для комплексного, гармоничного и непрерывного развития будущих педагогов в стратегическом контексте. 